\title{
SIFAT-SIFAT SPEKTRAL DAN STRUKTUR KOMBINATORIK PADA SISTEM POSITIF 2D
}

(On the Spectral and Combinatorial Structure Of 2D Positive Systems)

\author{
RUDY WOLTER MATAKUPAN \\ Staf Jurusan Matematika FMIPA UNPATTI \\ J1. Ir. M. Putuhena, Kampus Unpatti, Poka-Ambon \\ e-mail: rwmatakupan@yahoo.com
}

\begin{abstract}
The dynamics of a 2D positive system depends on the pair of nonnegative square matrices that provide the updating of its local states. In this paper, several spectral properties, like finite memory, separablility and property L, which depend on the characteristic polynomial of the pair, are investigated under the nonnegativity constraint and in connection with the combinatorial structure of the matrices.

Some aspects of the Perron-Frobenius theory are extended to the 2D case; in particular, conditions are provided guaranteeing the existence of a common maximal eigenvector for two nonnegative matrices with irreducible sum. Finally, some results on $2 \mathrm{D}$ positive realizations are presented.
\end{abstract}

Keywords: Finite Memory, 2D positive system, Separability, property L, Spectral properties

\section{PENDAHULUAN}

Sistem diskrit satu dimensi (1D) $x(h+1)=A x(h)+C u(h)$

$$
y(h)=H x(h)+J u(h) \quad h=0,1,2, \cdots
$$

adalah positif jika bagian masukan (input) dan keluaran (output) selalu bernilai tak-negatif. Sistem-sistem positif seringkali muncul karena variabel internal dan variabel eksternal, menunjukkan kuantitas sistem-sistem real, seperti tekanan, kosentrasi, tingkat populasi penduduk di suatu negara atau hewan di alam dan sebagainya.

Suatu penjelasan hampir lengkap dari sifat dinamis sistem diskrit telah disajikan dalam teorema PerronFrobenius yang hubungannya dengan spektral dan struktur kombinatorik matriks-matriks tak-negatif. Beberapa masalah baru muncul dalam konteks teori sistem, mendorong penelitian dan membuka pandangan baru atas lapangan matriks-matriks positif. Beberapa menyebutkan yang berhubungan dengan reabilitas dan analisis keterobservasian yang menyatakan ruang bagian (state space) sistem-sistem positif 1D.

Sistem-sistem linear yang berkaitan dengan dua variabel diskrit atau sistem dua dimensi (2D) terbit dalam literatur hampir dua puluh tahun yang lalu, para ahli mulai dengan menyelidiki struktur rekursif untuk proses data dua dimensi. Proses tersebut dilakukan menggunakan algoritma diskripsi masukan-keluaran lewat rasio polinomial dalam dua indeterminate. Ide baru yang bersumber dari penelitian sistem-sistem 2D terus dilakukan dengan mengingat algoritma-algoritma tersebut sebagai penyajian eksternal sistem-sistem dinamik, karena itu sistem 2D $\Sigma=(A, B, C, D, H, J)$, diberikan oleh persamaan (2).

$$
\begin{aligned}
x(h+1, k+1)= & A x(h, k+1)+B x(h+1, k) \\
& +C u(h, k+1)+D u(h+1, k) \\
y(h, k)= & H x(h, k)+J u(h, k)
\end{aligned}
$$

dimana $u(h, k) \in \mathrm{R}$ masukan, $y(h, k) \in \mathrm{R}$ keluaran, $h, k \in \mathrm{Z}, A, B \in \mathrm{R}^{n \times n}, C, D \in \mathrm{R}^{n \times 1}, H, J \in \mathrm{R}^{1 \times n}$ dan $x(h, k) \in \mathrm{R}^{n}$ merupakan ruang bagian lokal (local state space). (model Fornasini-Marchesini, 1976). Bentuk lain di luar persamaan di atas dikenal dalam model GivoneRoesser 1972, model Attasi 1973, model Roesser 1975 dan model Sontag 1978.

Para ahli mengaplikasikan untuk memproses data dua dimensi dalam berbagai bidang seperti Ilmu Gempa Bumi (Seismologi), peningkatan bayangan sinar $X$, bayangan baur, proses gambar digital dan sebagainya. Konstribusi lain dapat dijumpai pada model populasi sungai (Fornasini 1991), diambil sebagai contoh untuk batasan tak-negatif dalam persamaan (2) dan diskritisasi persamaan diferensial parsial dari penyerapan gas dan aliran air panas (Marszalek, 1984). 
Sistem positif 2D adalah suatu model bagian yang mengambil variabel-variabel bernilai positif. Disini akan dibatasi untuk bagian unforced pada sistem 2D (2) seperti yang diberikan persamaan :

$$
\begin{aligned}
x(h+1, k+1) & =A x(h, k+1)+B x(h+1, k) \\
y(h, k) & =H x(h, k)
\end{aligned}
$$

dimana barisan pasangan kembar indeks bagian lokal (local state) $x(\cdot, \cdot)$ diambil dalam daerah positif $\mathrm{R}_{+}^{n}=\left\{x \in \mathrm{R}^{n} \mid x_{i} \geq 0, i=1,2, \cdots, n\right\} \quad$ dengan $\quad h, k \in \mathrm{Z}$ sedangkan $A$ dan $B$ matriks-matriks tak-negatif berukuran $n \times n$. Kondisi awal (initial condition) ditetapkan oleh nilai-nilai tak-negatif dari bagian lokal pada himpunan terpisah (separation set) $\mathrm{C}_{0}=\{(i,-i) \mid i \in z\}$. Pilihan berbeda untuk kondisi awal dapat dianggap pada batas

$$
S=\{(i, 0) \mid i>0\} \cup\{(0, j) \mid j>0\}
$$

\section{TINJAUAN PUSTAKA}

Sistem linear diskrit 2D dalam bentuk (2) disusun oleh matematikawan Italy, Ettore Fornasini dan Giovanni Marchesini (1978) dengan artikel: State-Space Realization Theory of Two-Dimensional Filters, sedangkan sistem finite memory untuk sistem positif 2D diperkenalkan oleh Bisiacco (1985) dengan menyebutkan polinomial karakteristik $\Delta_{A, B}\left(z_{1}, z_{2}\right)=1$, berlaku untuk setiap $z_{1}$ dan $z_{2}$. Pengertian lain untuk menyebutkan sistem (2) sebagai sistem separable, yaitu jika dapat ditulis polinomial karakteristik sebagai $\Delta_{A, B}\left(z_{1}, z_{2}\right)=r\left(z_{1}\right) \cdot\left(z_{2}\right)$, dikemukakan oleh Ettore Fornasini dan Giovanni Marchesini (1993).

Selanjutnya dengan merujuk pada artikel Pairs of Matrices with Property $L$ oleh Motzkin dan Taussky (1952), yang telah mendefinisikan pasangan matriks $(A, B)$ ke dalam sifat-sifat $L$, kemudian dengan artikel dari Ettore Fornasini dan Maria Elena Valcher (1996), dengan dukungan beberapa litelatur menyusun sifat-sifat spektral dan struktur kombinatorik pada sistem positif 2D.

\section{HASIL DAN PEMBAHASAN}

\section{Sifat-sifat Spektral dan Struktur Kombinatorik pada Sistem Positif 2D}

Dalam proposisi berikut disajikan perkalian Hurwitz dan perkalian elemen-elemen dalam suatu monoid bebas $\Xi^{*}$ yang dibangun oleh $A$ dan $B$.

\section{Proposisi 1}

Misalkan $(A, B)$ pasangan matriks tak-negatif berukuran $n \times n$ maka pernyataan-pernyataan berikut saling ekuivalen

(i). $\quad \Delta_{A, B}\left(z_{1}, z_{2}\right)=1$

(ii). $A+B$ nilpoten (iii). $\quad A^{i} \omega^{j} B$ nilpoten untuk setiap $(i, j) \neq(0,0)$

(iv). $w(A, B)$ nilpoten untuk setiap $w \in \Xi^{*}-\{1\}$

Bukti :

Akan dibuktikan $(i) \Rightarrow(i i)$.Ambil $z_{1}=z_{2}=z$ maka $\operatorname{det}\left(I_{n}-(A+B) z\right)=1=\operatorname{det}\left(I_{n}\right) \quad$ yaitu dipenuhi jika $A+B=0$. Jadi $(A+B)^{v}=0$ untuk suatu $v \in \mathrm{Z}$ atau $A+B$ nilpoten terbukti.

Akan dibuktikan $\quad(i i) \Rightarrow($ iii $)$.Untuk setiap $\quad v \geq n$ berlaku

$$
\sum_{i+j=v} A^{i}{ }^{j}{ }_{B}=(A+B)^{v}
$$

karena $A+B$ nilpoten dan tak-negatif maka $A^{i}$ ш $j_{B=0}$ dimana $i+j=v \geq n$, akibatnya $A^{i n} ш$ ${ }^{j n} B=0$. Dengan memperhatikan hubungan $0 \leq\left(A^{i}\right.$ ш $\left.j_{B}\right)^{n} \leq A^{i n}{ }^{j n}{ }_{B=0} \quad \forall(i, j) \neq(0,0) \quad$ maka $\quad\left(A^{i}\right.$ ш $j_{B)}^{n}=0$ atau $A^{i}{ }^{j}{ }_{B}$ nilpoten terbukti.

Akan dibuktikan $\quad(i i i) \Rightarrow(i v)$.Misalkan $|w|_{1}=i$ dan $|w|_{2}=j$. Perkalian Hurwitz ke- $(i, j)$.

$A^{i}{ }_{\text {ш }}^{j} B=\sum_{|w| 1}=i,|w|_{2}=j w(A, B) \geq w(A, B) \quad$ sehingga $\left(A^{i}{ }^{j}{ }_{B}\right)^{n} \geq[w(A, B)]^{n} \geq 0$ untuk suatu $n \in \mathrm{Z}$. Karena $A^{i}{ }_{\text {ш }}^{j}{ }_{B}$ nilpoten atau $\left(A^{i}{ }^{j}{ }_{B}\right)^{n}=0 \quad$ maka $[w(A, B)]^{n}=0$, yaitu $w(A, B)$ nilpoten $w \in \Xi^{*}-\{1\}$ terbukti.

Kemudian, akan dibuktikan $(i v) \Rightarrow(i)$. Menggunakan teorema Levitzki, $\boldsymbol{w}(\boldsymbol{A}, \boldsymbol{B})$ nilpoten maka dengan transformasi similaritas matriks-matriks $A$ dan $B$ direduksi ke bentuk matriks-matriks segitiga. Polinomial karakteristik: $\Delta_{A, B}\left(z_{1}, z_{2}\right)=\prod_{i=1}^{n}\left(1-A_{i i} z_{1}-B_{i i} z_{2}\right)$.

Ambil $z_{1}=z_{2}=z$, diketahui $A+B$ nilpoten maka $\Delta_{A, B}\left(z_{1}, z_{2}\right)=\prod_{i=1}^{n}\left(1-\left(A_{i i}+B_{i i}\right) z\right)=1$ terbukti.

Jadi (i), (ii), (iii) dan (iv) saling ekuivalensi $\square$

\section{Definisi 2}

Suatu pasangan matriks $(A, B)$ berukuran $n \times n$ dikatakan ko-gradien ke pasangan $(\bar{A}, \bar{B})$, jika terdapat suatu matriks permutasi $\mathrm{P}$ sehingga

$$
\bar{A}=P^{T} \text { AP dan } \bar{B}=P^{T} \text { BP }
$$

Struktur kombinatorik sistem finite memory dari pasangan-pasangan matriks tak- negatif dijelaskan secara lengkap pada proposisi berikut ini. 


\section{Proposisi 3}

Pasangan matriks tak-negatif $(A, B)$ berukuran $n \times n$ finite memory jika dan hanya jika $(A, B)$ ko-gradien untuk suatu matriks segitiga atas nilpoten tak-negatif.

Bukti :

$(\Rightarrow)$ Telah diketahui pada proposisi 1 , jika $(A, B)$ finite memory maka $(A+B)$ nilpoten akibatnya $(A+B)$ tereduksi dengan demikian terdapat matriks permutasi $P$ sehingga $P^{T}(A+B) P=\overline{(A+B)}$. Akan ditunjukkan bahwa $\overline{(A+B)}$ matriks segitiga atas dengan diagonal nol. Misalkan $\lambda_{1}$ nilai karakteristik dari matriks $A+B$ dan $x_{1} \in V_{n}(\mathrm{R})$ vektor karakteristik yang bersesuaian dengan $\lambda_{1}$ sehingga $(A+B) x_{1}=\lambda_{1} x_{1}$ dan $x_{1}^{t} x_{1}=1$. Anggap matriks permutasi itu sebagai $P_{1}=\left(x_{1}, x_{2}, \ldots, x_{n}\right)$ sehingga

$$
P_{1}^{T}(A+B) P_{1}=\left[\begin{array}{c:c}
(A+B)_{11} & * \\
\hdashline 0 & (A+B)_{22}
\end{array}\right]
$$

dengan $x_{i}^{t} x_{1}=0, i \neq 1$. Dan seterusnya akan didapat

$$
P_{k}^{T}(A+B)_{k-1, k-1} P_{k} \quad k=3,4, \cdots, n-1 .
$$

Sekarang bila matriks ortogonal $\left[\begin{array}{cc}I & 0 \\ 0 & P_{2}\end{array}\right]$ berukuran $n \times n$ sedemikian hingga

$$
\begin{aligned}
{\left[\begin{array}{ll}
I & 0 \\
0 & P_{2}
\end{array}\right]^{T} P_{1}^{T}(A+B) P_{1}\left[\begin{array}{cc}
I & 0 \\
0 & P_{2}
\end{array}\right] } \\
=\left[\begin{array}{cc:c}
(A+B)_{11} & * & * \\
0 & (A+B)_{22} & * \\
\hdashline 0 & 0 & (A+B)_{33}
\end{array}\right]
\end{aligned}
$$

Jika dilanjutkan diperoleh matriks permutasi

$$
P=P_{1}\left[\begin{array}{cc}
I & 0 \\
0 & P_{2}
\end{array}\right]\left[\begin{array}{cc}
I & 0 \\
0 & P_{3}
\end{array}\right] \cdots\left[\begin{array}{cc}
I & 0 \\
0 & P_{n-1}
\end{array}\right]
$$

karena $A+B$ nilpoten maka

$$
\begin{aligned}
P^{T}(A+B) P & =\left[\begin{array}{ccccc}
(A+B)_{11} & * & \cdots & * \\
0 & (A+B)_{22} & \cdots & * \\
\vdots & & \vdots & \ddots & \vdots \\
0 & & 0 & \cdots & (A+B)_{n n}
\end{array}\right] \\
& =\left[\begin{array}{ccccc}
0 & * & \cdots & \cdots & * \\
0 & 0 & \cdots & \cdots & * \\
\vdots & \vdots & \ddots & & \vdots \\
\vdots & \vdots & & \ddots & * \\
0 & 0 & \cdots & \cdots & 0
\end{array}\right]=(A+B)
\end{aligned}
$$

Jadi $(A, B)$ ko-gradien untuk suatu matriks segitiga atas tak-negatif , terbukti.
$(\Leftarrow)$ Dari bentuk matriks di atas maka $(A+B)^{n}=0$ untuk suatu $n \in \mathrm{Z}$ atau $A+B$ nilpoten, menurut proposisi 1 pasangan $(A, B)$ finite memory terbukti $\square$

Dalam menganalisis pasangan separable tak-negatif, dilakukan mengikuti alur yang sama dengan finite memory. Suatu dekomposisi spektral separable diringkas sebagai berikut:

\section{Proposisi 4}

Misalkan $(A, B)$ pasangan matriks positif berukuran $n \times n$ maka pernyataan-pernyataan berikut saling ekuivalen

(i). $\quad \Delta_{A, B}\left(z_{1}, z_{2}\right)=r\left(z_{1}\right) \cdot s\left(z_{2}\right)$

(ii). $\operatorname{det}[I-(A+B) z]=\operatorname{det}[I-A z] \cdot \operatorname{det}[I-B z]$

(iii). $A^{i}{ }^{j}{ }_{B}$ nilpoten untuk setiap $i, j>0$

(iv). $w(A, B)$ nilpoten untuk setiap $w \in \Xi^{*}-\{1\}$ sehingga $|w|_{i}>0 i=1,2$

(v). Terdapat suatu matriks tak-singular $T \in \mathrm{C}^{n \times n}$ sehingga $\hat{A}=T^{-1} A T$ dan $\hat{B}=T^{-1} B T$ merupakan matriks-matriks segitiga atas dan $[\hat{A}]_{h h} \neq 0$ sehingga berlaku $[\hat{B}]_{h h}=0$.

Bukti :

Akan dibuktikan $(i) \Rightarrow($ ii $)$. Jika

$$
z_{1}=0 \Rightarrow \Delta_{A, B}\left(z_{1}, z_{2}\right)=\operatorname{det}\left[I-B z_{2}\right] \equiv s\left(z_{2}\right)
$$

dan jika

$$
z_{2}=0 \Rightarrow \Delta_{A, B}\left(z_{1}, z_{2}\right)=\operatorname{det}\left[I-A z_{1}\right] \equiv r\left(z_{1}\right) .
$$

Diambil $z_{1}=z_{2}=z$, maka

$$
\begin{aligned}
\Delta_{A, B}\left(z_{1}, z_{2}\right) & =\operatorname{det}[I-(A+B) z] \\
& =r\left(z_{1}\right) \cdot s\left(z_{2}\right)=\operatorname{det}[I-A z] \cdot \operatorname{det}[I-B]
\end{aligned}
$$

terbukti.

Kemudian, akan dibuktikan $(i i) \Rightarrow($ iii $)$. Dimulai dengan memperhatikan matriks

$$
M=\left[\begin{array}{ll}
A & 0 \\
0 & B
\end{array}\right]
$$

$\operatorname{det}[I-(A+B) z]=\operatorname{det}[I-A z] \cdot \operatorname{det}[I-B z]=\operatorname{det}[I-M z]$ sehingga $M$ dan $A+B$ mempunyai polinomial karakteristik yang sama, akibatnya

$$
\operatorname{tr}\left(M^{h}\right)=\operatorname{tr}\left((A+B)^{h}\right) \quad \forall h \geq 1
$$

perhatikan bahwa $(A+B)^{h}=\sum_{i+j=h} A^{i}{ }^{j} B$ merupakan linieritas dari operator trace.

$$
\operatorname{tr}\left(A^{h}\right)+\operatorname{tr}\left(B^{h}\right)=\sum_{i+j=h} \operatorname{tr} A^{i} \omega^{j} B
$$


Diketahui $\sum_{i, j>0, i+j=h} t r \quad A^{i}{ }^{j}{ }^{j} B=0 \quad \forall h \geq 1$ sehingga pasangan $(A, B)$ tak-negatif. Akhirnya untuk $h \geq v$

$$
0 \leq \operatorname{tr}\left(\left(A^{i}{ }^{j} B\right)^{v}\right) \leq \operatorname{tr}\left(A^{i v}{ }^{j v} B\right)=0
$$

untuk $i, j \geq 1 ; v=1,2, \ldots$

maka $\left(A^{i}{ }^{j} B\right)^{\nu}=0$ atau $A^{i}{ }^{j}{ }_{B}$ nilpoten untuk setiap $i, j>0$ terbukti.

Bukti (iii) $\Rightarrow$ (iv) mirip dengan pembuktian (iii) $\Rightarrow$ (iv) pada proposisi 1 terbukti.

Akan dibuktikan $(i v) \Rightarrow(v)$. Karena $w(A, B)$ nilpoten $w \in \Xi^{*}-\{1\},|w|_{i}>0 i=1,2$ menurut proposisi 1 pasangan matriks tak-negatif $(A, B)$ finite memory dan menurut proposisi $4(A, B)$ ko-gradien untuk suatu matriks segitiga terbatas ke atas, maka terdapat $T \in \mathrm{C}^{n \times n}$ sehingga $\hat{A}=T^{-1} A T$ dan $\hat{B}=T^{-1} B T$ dimana $\hat{A}$ dan $\hat{B}$ matriks-matriks segitiga atas. Sekarang akan ditunjukkan $[\hat{A}]_{h h} \neq 0 \Rightarrow[\hat{B}]_{h h}=0 \quad$ menggunakan perluasan teorema Levitzki. Misalkan $A, B \in \mathrm{C}^{n \times n}$ dan $S$ himpunan semua perkalian matriks pada semigrup

$$
\begin{aligned}
S & =\left\{\left.w(A, B)\left|w \in \Xi^{*},\right| w\right|_{1} \geq 1,|w|_{2} \geq 1\right\} \\
& =\{\hat{A} . \hat{A} \cdots \hat{A}, \hat{B} \cdot \hat{B} \cdots \hat{B}\} .
\end{aligned}
$$

Menurut Levitzki $w(A, B)$ nilpoten jika dan hanya jika $(A, B)$ separable dan merupakan matriks segitiga melalui suatu transformasi similaritas.

$$
\operatorname{tr}(w(A, B))=\operatorname{tr}\left([\hat{A}]^{i} \cdot[\hat{B}]^{j}\right)=\sum_{h=1}^{n}\left([\hat{A}]_{h h}\right)^{i}\left([\hat{A}]_{h h}\right)^{j}=0
$$

Persamaan (5) benar jika $[\hat{A}]_{h h} \neq 0$ maka $[\hat{B}]_{h h}=0$; $h=1,2, \cdots, n$ terbukti.

Akan dibuktikan $(v) \Rightarrow(i)$. Karena $\hat{A}$ dan $\hat{B}$ masingmasing matriks segitiga atas maka nilai-nilai eigen mereka dapat di order sebagai spektra

dan

$$
\Lambda(\hat{A})=\left(\hat{A}_{11}, \hat{A}_{22}, \cdots, \hat{A}_{n n}, 0,0, \cdots, 0\right)
$$

$$
\Lambda(\hat{B})=\left(0, \quad 0, \cdots, 0, \hat{B}_{n+1, n+1}, \cdots, \hat{B}_{r r}\right)
$$

sehingga untuk setiap $\alpha, \beta \in \mathrm{C}$ didapat

$$
\begin{aligned}
\Lambda(\alpha \hat{A}+\beta \hat{B}) & \left.=\left(\alpha \hat{A}_{11}, \alpha \hat{A}_{22}, \cdots, \alpha \hat{A}_{n n}, \beta \hat{B}_{n+1, n+1}, \beta \hat{B}_{n+2, n+2}, \cdots, \beta \hat{B}_{r r}\right)\right) \\
& =\alpha \Lambda(\hat{A})+\beta \Lambda(\hat{B}
\end{aligned}
$$

jadi $\hat{A}$ dan $\hat{B}$ mempunyai sifat $L$, dketahui $(\hat{A}, \hat{B})$ separable karena $\hat{A} \approx A, \hat{B} \approx B$ maka $(A, B)$ separable terbukti.

Dengan demikian (i), (ii), (iii), (iv) dan (v) saling ekuivalensi $\square$

Struktur kombinatorik pasangan-pasangan matriks separable sangat menarik dan mudah ditentukan sebagai akibat lemma berikut.

\section{Lemma 5}

Jika $A>0$ dan $B>0$ pasangan matriks separable berukuran $n \times n$ maka $A+B$ tereduksi.

\section{Proposisi 6}

Pasangan matriks tak-negatif $(A, B)$ berukuran $n \times n$ separable jika dan hanya jika terdapat matriks permutasi $\mathrm{P}$ sehingga $P^{T} A P$ dan $P^{T} B P$ terpecah ke dalam matriks segitiga blok

$$
\begin{aligned}
& \hat{A}=\left[\begin{array}{cccc}
A_{11} & * & \cdots & * \\
0 & A_{22} & \cdots & * \\
\vdots & \vdots & \ddots & * \\
0 & 0 & \cdots & A_{t t}
\end{array}\right] \\
& \hat{B}=\left[\begin{array}{cccc}
B_{11} & * & \cdots & * \\
0 & B_{22} & \cdots & * \\
\vdots & \vdots & \ddots & * \\
0 & 0 & \cdots & B_{t t}
\end{array}\right]
\end{aligned}
$$

dimana $A_{i i} \neq 0$ maka $B_{i i}=0$.

Bukti :

$(\Rightarrow)$ Jika salah satu dari pasangan $(A, B)$ adalah matriks nol maka trivial. Jika pasangan $(A, B)$ tak-nol dan separable menurut lemma 5 maka $A+B$ tereduksi sehingga terdapat matriks permutasi $P_{1}=\left(x_{1}, x_{2}, \ldots, x_{n}\right)$. Misalkan $\lambda_{1}$ nilai karakteristik dari $A+B$ dan $x_{1} \in V_{n}(\mathrm{R})$ vektor karakteristik yang bersesuaian dengan $\lambda_{1}$ sehingga

$$
A x_{1}=\lambda_{1} x_{1} \text { dan } x_{1}^{t} x_{1}=1
$$

Matriks ortogonal $P_{1}$ berukuran $(n-1) \times(n-1)$,

$$
\begin{aligned}
P_{1}^{T}(A+B) P_{1} & =P_{1}^{T} A P_{1}+P_{1}^{T} B P_{1} \\
& =\left[\begin{array}{cc}
A_{11} & A_{12} \\
0 & A_{22}
\end{array}\right]+\left[\begin{array}{cc}
B_{11} & B_{12} \\
0 & B_{22}
\end{array}\right]
\end{aligned}
$$

dimana $P_{1}^{T} A P_{1}=\left[\begin{array}{c:c}A_{11} & A_{12} \\ \hdashline 0 & A_{22}\end{array}\right]$ untuk $i \neq 1, \quad x_{i}{ }^{t} x_{1}=0$ dan $P_{1}^{T} B P_{1}=\left[\begin{array}{c:c}B_{11} & B_{12} \\ \hdashline 0 & B_{22}\end{array}\right]$.

Jika diteruskan pada akhirnya akan didapat,

$$
P_{n-1}^{T} A_{n-1, n-1} P_{n-1}=\left[\begin{array}{c:c}
A_{n-1, n-1} & A_{n-1, n} \\
\hdashline 0 & A_{n n}
\end{array}\right]
$$

dan

$$
P_{n-1}^{T} B_{n-1, n-1} P_{n-1}=\left[\begin{array}{c:c}
B_{n-1, n-1} & B_{n-1, n} \\
\hdashline 0 & B_{n n}
\end{array}\right]
$$

Sehingga

$$
P_{n-1}^{T}\left(A_{n-1, n-1}+B_{n-1, n-1}\right) P_{n-1}=P_{n-1}^{T} A_{n-1, n-1} P_{n-1}+P_{n-1}^{T} B_{n-1, n-1} P_{n-1}
$$


Kemudian akan diperoleh matriks permutasi

$$
P=P_{1}\left[\begin{array}{cc}
I & 0 \\
0 & P_{2}
\end{array}\right]\left[\begin{array}{cc}
I & 0 \\
0 & P_{3}
\end{array}\right] \cdots\left[\begin{array}{cc}
I & 0 \\
0 & P_{n-1}
\end{array}\right]
$$

Sehingga diperoleh (6). Dengan melakukan cara yang sama seperti di atas didapat $P^{T} B P$ seperti pada (6) sehingga

$$
\begin{aligned}
& P^{T}(A+B) P=P^{T} A P+P^{T} B P \\
& =\left[\begin{array}{cccc}
A_{11}+B_{11} & * & \cdots & * \\
0 & A_{22}+B_{22} & \cdots & * \\
\vdots & \vdots & \ddots & * \\
0 & 0 & \cdots & A_{n n}+B_{n n}
\end{array}\right]
\end{aligned}
$$

menurut proposisi $4(\mathrm{v}) A_{i i} \neq 0$ maka berlaku $B_{i i}=0$, terbukti.

$(\Leftarrow)$ Jelas menurut proposisi $4(v) \Rightarrow(i)$, terbukti $\square$

Masalah invers spektral untuk pasangan-pasangan matriks-matriks tak-negatif dapat ditetapkan dengan membuat pertanyaan sebagai berikut : apa syarat perlu dan cukup untuk suatu polinomial dalam dua variabel $p\left(z_{1}, z_{2}\right)=1-\sum_{i+j>0} p_{i j} z_{1}^{i} z_{2}^{j}$ ke polinomial karakteristik dari pasangan matriks tak-negatif $(A, B)$ ? Berikut lemma yang buktinya merupakan algoritma untuk memecahkan masalah invers spektral 2D.

\section{Lemma 7}

Misalkan $\quad p\left(z_{1}, z_{2}\right)=1-\sum_{i+j>0} p_{i j} z_{1}^{i} z_{2}^{j} \in R\left[z_{1}, z_{2}\right]$; $\mathrm{r}$ dan $\mathrm{s}$ bilangan-bilangan bulat yang memenuhi $\operatorname{deg}_{z_{1}}(p) \leq r, \operatorname{deg}_{z_{2}}(p) \leq s, \operatorname{deg}(p) \leq r+s-1 \quad$ maka terdapat pasangan matriks $(A, B)$ berukuran $(r+s-1) \times(r+s-1)$ yang memenuhi

$$
\Delta_{A, B}\left(z_{1}, z_{2}\right)=p\left(z_{1}, z_{2}\right)
$$

setiap koefisien $p_{i j}$ tak-negatif dan setiap elemen $(A, B)$ dapat dipilih tak-negatif.

\section{Proposisi 8}

Jika semua koefisien-koefisien $p_{i j}$ dalam polinomial $p\left(z_{1}, z_{2}\right)=1-\sum_{i+j>0} p_{i j} z_{1}{ }^{i} z_{2}^{j} \in R\left[z_{1}, z_{2}\right]$ tak-negatif, maka terdapat pasangan matriks tak-negatif $(A, B)$ dengan $A+B$ tak-tereduksi sehingga

$$
\Delta_{A, B}\left(z_{1}, z_{2}\right)=p\left(z_{1}, z_{2}\right) \text { dipenuhi. }
$$

Bukti :

Misalkan $\operatorname{deg}_{z_{1}}(p) \leq r, \operatorname{deg}_{z_{2}}(p) \leq s$ dan yang pertama $r+s>\operatorname{deg}(p)$, menurut lemma 7 dapat dikonstruksikan dua matriks tak-negatif $A$ dan $B$ berdimensi $(r+s-1) \times(r+s-1) \quad$ sehingga memenuhi $\Delta_{A, B}\left(z_{1}, z_{2}\right)=p\left(z_{1}, z_{2}\right)$. Dalam matriks $M=A+B$, paling sedikit terdapat elemen tak-nol $m_{1, k}, k \geq r$ dalam baris pertama dan elemen tak-nol $m_{i+1,1}$ adalah 1 dengan bilangan-bilangan bulat positif $i, j \leq r+s-1$. Digraph $D(M)$ merupakan suatu path dari vertex $i$ ke vertex $j$ dengan $i, j \leq r+s-1$ dua bilangan bulat positif. Jika $i<j$ maka trivial, tetapi jika $i>j$ maka terdapat $\gamma=\{(i, i-1),(i-1, i-2), \cdots,(1, k),(k, k-1), \cdots,(\rho+1, \rho)$,

$$
(\rho, r+s-1),(r+s-1, r+s-2), \cdots,(j+1, j)\}
$$

untuk itu matriks $M$ tak-tereduksi. Jika $\operatorname{deg}(p)=r+s$, anggap $p\left(z_{1}, z_{2}\right)$ mempunyai derajat formal $r+1$ dalam $z_{1}$, kemudian dengan mengulangi konstruksi seperti pada lemma 7 akan didapat matriks tak-negatif berdimensi $r+s$ terbukti.

Jelas bahwa $M$ tak-tereduksi, sebab andaikan $M$ tereduksi maka berlaku $\left[M^{k}\right]_{i j}=0$ untuk suatu bilangan bulat positif $k$, padahal diketahui bahwa $\left[M^{k}\right]_{i i}=1$ kontradiksi, jadi $M$ harus tak-tereduksi dengan demikian bukti lengkap $\square$

Syarat cukup untuk memecahkan masalah invers spektral adalah masalah invers spektral 1D. Keadaan khusus yang harus menjadi perhatian :

1. Dalam $\quad p\left(z_{1}, 0\right)=\prod_{i=1}^{n}\left(1-\lambda_{i} z_{1}\right) \quad$ dan $p\left(0, z_{2}\right)=\prod_{i=1}^{n}\left(1-\mu_{i} z_{2}\right) \quad$ dimana $\mu_{i}, \lambda_{i} \in \mathrm{R}, \quad \forall i$ dan memenuhi syarat Suleimanova untuk memecahkan masalah invers spektral 1D

$$
\begin{array}{ll}
\lambda_{1}>0 \geq \lambda_{i} \quad \forall i \geq 2 \text { dan } \sum_{i=1}^{n} \lambda_{i}>0 \\
\mu_{1}>0 \geq \mu_{i} \quad \forall i \geq 2 \text { dan } \sum_{i=1}^{n} \mu_{i}>0
\end{array}
$$

2. Faktor-faktor $p\left(z_{1}, z_{2}\right)$ ke dalam perkalian faktor linier sebagai

$$
p\left(z_{1}, z_{2}\right)=\prod_{i=1}^{n}\left(1-\lambda_{i} z_{1}-\mu_{i} z_{2}\right)
$$

Ketika (8) dan (9) dipenuhi maka masalah invers spektral 2D terpecahkan dan suatu penyelesaian $(A, B)$ dapat dibangun dengan $A+B$ tak-tereduksi.

Dengan menggunakan lemma 7 dan proposisi 8, akan dilakukan reduksi untuk membuktikan koefisienkoefisien $p_{i j}$ pada $p\left(z_{1}, z_{2}\right)$ tak-negatif, diberikan dalam proposisi berikut

\section{Proposisi 9}

Misalkan $\lambda_{i}$ dan $\mu_{i}, i=1,2, \cdots, n$ bilangan-bilangan real yang memenuhi (8) maka dalam polinomial $p\left(z_{1}, z_{2}\right)=\prod_{i=1}^{n}\left(1-\lambda_{i} z_{1}-\mu_{i} z_{2}\right)=1-\sum_{i+j=1}^{n} p_{i j} z_{1}^{i} z_{2}^{j}$ semua koefisien-koefisien $p_{i j}$ tak-negatif. 
Sebagai akibat dari proposisi-proposisi di atas tersedia algoritma untuk memperlihatkan contoh taktrivial dari pasangan positif.

\section{Contoh 1}

Misalkan diberikan polinomial :

$$
p\left(z_{1}, z_{2}\right)=\left(1-z_{1}-z_{2}\right)\left(1+\frac{z_{1}}{2}+\frac{z_{2}}{2}\right)\left(1+\frac{z_{1}}{4}\right),
$$

disini akan ditentukan pasangan matriks $(A, B)$ berukuran $4 \times 4$, dengan jumlahan tak-tereduksi yang memenuhi (7). Pasangan $(A, B)$ mempunyai sifat $L$ dan nilai-nilai eigen mereka mengikuti orde spektra $\Lambda(A)=(1,-1 / 2,-1 / 4,0)$ dan $\Lambda(B)=(1,-1 / 2,0,0)$, kemudian $p\left(z_{1}, z_{2}\right)$ dapat ditulis kembali sebagai

$$
\begin{aligned}
p\left(z_{1}, z_{2}\right)= & 1-\left(\frac{3}{4} z_{1}+\frac{1}{2} z_{2}\right)-\left(z_{1}\left(\frac{5}{8} z_{1}+\frac{5}{8} z_{2}\right)+z_{2}\left(\frac{1}{2} z_{1}+\frac{1}{2} z_{2}\right)\right) \\
& -\left(z_{1}^{2}\left(\frac{1}{8} z_{1}+\frac{1}{8} z_{2}\right)+z_{1} z_{2}\left(\frac{1}{8} z_{1}+\frac{1}{8} z_{2}\right)\right)
\end{aligned}
$$

menggunakan koefisien-koefisien dari bentuk-bentuk linear untuk konstruksi matriks-matriks $A$ dan $B$ menurut lemma 7 maka

$$
L\left(z_{1}, z_{2}\right)=\left[\begin{array}{cccc}
1 & 0 & -1 / 8 z_{1}-1 / 8 z_{2} & 0 \\
-z_{1} & 1 & -5 / 8 z_{1}-5 / 8 z_{2} & -1 / 8 z_{1}-1 / 8 z_{2} \\
0 & -z_{2} & 1-3 / 4 z_{1}-1 / 2 z_{2} & -1 / 2 z_{1}-1 / 2 z_{2} \\
0 & 0 & -z_{2} & 1
\end{array}\right]_{4 \times 4}
$$

memenuhi det $L\left(z_{1}, z_{2}\right)=p\left(z_{1}, z_{2}\right)$ maka diperoleh

$$
A=\left[\begin{array}{cccc}
0 & 0 & 1 / 8 & 0 \\
1 & 0 & 5 / 8 & 1 / 8 \\
0 & 1 & 3 / 4 & 1 / 2 \\
0 & 0 & 0 & 0
\end{array}\right]
$$

dan

$$
B=\left[\begin{array}{cccc}
0 & 0 & 1 / 8 & 0 \\
0 & 0 & 5 / 8 & 1 / 8 \\
0 & 0 & 1 / 2 & 1 / 2 \\
0 & 0 & 1 & 0
\end{array}\right]
$$

\section{KESIMPULAN}

Dari pembahasan dapat disimpulkan bahwa :

1. Dekomposisi spektral dari pasangan matriks finite memory dan separable sistem 2D dapat dibentuk seperti ditunjukkan pada proposisi 1 dan proposisi 5 .

2. Pasangan matriks $(A, B)$ tak-negatif berukuran $n \times n$ yang finite memory dan separable berturutturut dengan syarat: $A+B$ tereduksi dan $A, B>0$, merupakan syarat perlu agar pasangan-pasangan tersebut ko-gradien ke suatu matriks segitiga atas.

3. Pasangan $(A, B)$ mempunyai sifat $L$ dimana $A$ matriks diagonal dengan elemen-elemen berbeda dan $B$ matriks tak-negatif sesuai dengan partisi $A$ maka $(A, B)$ akan ko-gradien ke suatu matriks segitiga atas.

4. Invers spektral $2 \mathrm{D}$ pasangan matriks $(A, B)$ dapat dipecahkan jika memenuhi syarat-syarat Suleimanova untuk invers spektral 1D dan polinomial :

$$
p\left(z_{1}, z_{2}\right)=\prod_{i=1}^{n}\left(1-\lambda_{i} z_{1}-\mu_{i} z_{2}\right)
$$

\section{DAFTAR PUSTAKA}

Bose, N.K., 1982, Applied Multidimentional system Theory, Van Nostrand Reinhold, New York

Bisiacco, M., 1985, State and output feedback stabilizability of 2D systems, IEEE Trans. Circ. Sys., vol CAS-32, pp. 1246-54.

Cullen, C.G., 1966, Matrices and Linear Transformations, Addison-Wesley Publising Company.

Davis P.J,1979, Circulant Matrices, John Wiley \& Sons.

Drazin, M.P, 1950, Some generalizations of matrix commutativity, Proc. London Math. Soc.,(3),1, 22231.

Fornasini,E. and Machesini,G., 1976, State-Space Realization Theory Of Two-Demensional Filters, IEEE Trans.Aut.Contr,vol.AC-21,484-492.

Fornasini,E. and Machesini,G., 1978, Doubly-Indexed Dynamical systems : State-Space Models and Tructural Properties, Math.Systems .Teory, vol. 12, 59-72.

Fornasini,E. and Machesini,G., 1993, 2D state dynamics and geometry of the matrix pairs, in multivariate Analysis, Future Directions, C.R. Rao ed., Elsevier Sci.Publ.,pp. 131-53.

Fornasini,E., Marchesini,G., and Valcher,M.E., 1994, On The Structure of Finite Memory and Separable TwoDimensional Systems, Automatica, vol. 30, 347-350.

Fornasini,E., and Valcher,M.E.,1994, Matrix Pairs in Two-Dimensional Systems : an Approach Based on Trace Series an Hankel Matrices, to appear in SIAM J. Contr.Opt.

Fornasini,E., 1991, A 2D systems approach to river pollution modelling, Multid. Sys. Sign. Process., 2, pp.233-65

Frank Ayres, 1974, Theory and Problems of Matrices, McGraw-Hill, Inc.

Grantmacher, F.R., 1960, The Theory of Matrices, Chelsea Pub.Co., Vol. 2

Gilbert W.J., 1976, Modern Algebra With Applications, John Wiley \& Sons.

Luenberger, D.G., Introduction to dynamical systems, J. Wiley \& Sons Inc., 1979.

Motzkin,T.S., and Taussky,O., 1952, Pairs of Matrices With property L(1), Trans.Amer.Scc., vol.73. 108114.

Orlob, G.T,. 1983, Mathematical Modeling of Water Quality: Steams, Lakes, dan Reservoirs, International Institute for Applied Systems Analysis.

Soehakso,R.M.J.T., Teori Graph, Diktat .Kuliah MIPA UGM. 
Valcher,M.E., and Fornasini,E., 1994, State Models and Asymptotic Behavior of Two-Dimensional Positive Systems, to Appear in IMA J. of Appl.Math.

Varga, R.S., 1962, Matrix Iterative Analysis, PrenticeHall, inc. 